THE RING 31, 2 (2009) DOI 10.2478/v10050-008-0052-8

\title{
WINTERING RANGE OF THE BLACKCAP (Sylvia atricapilla) IN EUROPE - STABILIZED OR CHANGING?
}

\author{
Katarzyna Mokwa
}

\begin{abstract}
Mokwa K. 2009. Wintering range of the Blackcap (Sylvia atricapilla) in Europe - stabilized or changing? Ring 31, 2: 45-58.

So far the expansion of the Blackcap wintering range could not have been confirmed based on the analysis of ringing recovery data. The aims of this work was to define present boundaries of regular wintering area of the Blackcap in Europe and to find out whether the wintering range of the species has expanded over the last decades. A comparison of the Blackcap return rate in different parts of wintering area in subsequent winters was based on the probability distribution analysis. Dates of the Blackcap recoveries in different areas were also compared. Changes in number of winter recoveries from Great Britain as well as from regions to the north and south of the delimited northern boundary of the species regular wintering area were analysed as well.

Blackcaps ringed in winter in Scandinavia did not return to this area in the following winters. Percent share of such individuals in Central-Western Europe was low. Birds were recorded in these regions mainly at the beginning of winter. The Blackcap return rate both in Great Britain and in southern Europe was very high; birds were observed there throughout the whole winter. Over the last decades of the $\mathrm{XX}^{\text {th }}$ century the numbers of winter recoveries grew to a similar extent in the areas located to the north and south of the northern boundary of the Blackcap regular wintering area. Only in Great Britain this increase was faster. Based on the ringing recovery data analysis it can only be concluded that the regular wintering area of the Blackcap in Europe is most probably limited to the territories of the Mediterranean Sea basin. Most winter recoveries from other parts of Europe are probably only unsuccessful wintering attempts.
\end{abstract}

K. Mokwa, Museum and Institute of Zoology, Wilcza 64, PL-00-679 Warszawa, Poland; Nadwiślańska 108, 80-680 Gdańsk, Poland, E-mail: kasia@miiz.waw.pl; Bird Migration Research Station, University of Gdańsk, Przebendowo, PL-84-210 Choczewo, Poland

Key words: Blackcap, Sylvia atricapilla, migration, wintering range, recoveries 


\section{INTRODUCTION}

Wintering range of the Blackcap in Europe has changed a lot quite recently and most probably it is still changing. In the 1970 s Klein et al. (1973) proposed the $+10^{\circ} \mathrm{C}$ January isotherm as the northern boundary of the species wintering area. According to this limitation the Blackcap wintering range could cover only the southern edges of the largest southern European peninsulas. Nevertheless, in the case of this species it is very difficult to distinguish its regular wintering range from the areas where birds try to spend winter but most of them do not survive throughout this season. Since the 1950-1960s the number of reports on Blackcaps wintering in the areas located farther to the north has been growing up (Yeatman-Berthelot 1991, Berndt 1996, Johansen 2002). The Blackcap wintering range limit proposed by Harrison (1982) covered whole south-western Europe, from the Iberian Peninsula to the Balkans, as well as the southern part of Great Britain.

Regular increase in a number of wintering Blackcaps in Europe was most pronounced in Great Britain (Berthold et al. 1992, Berthold 1995). This area was recognized as a new, regular wintering ground of the species. Moreover, birds wintering in the British Isles did not originate from the local breeding population, but they were individuals that migrated from European continent in autumn (Berthold and Terrill 1988, Busse 1992, Berthold 1995). A number of winter recoveries of the Blackcap increased also in Central Europe, and even in Scandinavia, although not so quickly as in Great Britain (Górski et al. 1980, Lafferère 1987, Fransson and Stolt 1994, Sovinc 1994, Bauer et al. 1995, Pannach 2001, Tomiałojć and Stawarczyk 2003). This noticeable increase in a number of winter observations of Blackcaps resulted in a new delimitation of the species wintering grounds, given in recent publications (Cramp 1992, Snow and Perrins 1998), which included whole western Europe, and even Denmark. However, the proposed wintering range of the Blackcap should be treated with caution when considering winter conditions in these regions.

The aim of this analysis was to define present boundary of regular wintering area of the Blackcap in Europe and to find out whether wintering range of the species has expanded over the last decades.

\section{MATERIAL AND METHODS}

Altogether 2054 recoveries of Blackcaps reported during winter were used in this analysis. Most of these data were obtained from the Euring Data Bank thanks to cooperation of European Central Ringing Offices, and a part of them were found in available publications. All analysed recoveries were from 1931-2001. A period of 1 November - 29 February was defined as the standard wintering season.

An initial stage of the analysis was the delimitation of the northern boundary of the Blackcap wintering area based on spatial distribution of the recoveries in winter. The whole wintering season (1 Nov. - 29 Feb.) was divided into short, ten-day periods, 
and the recovery distribution in the southern part of Europe was analysed in these defined periods. The boundary location was determined according to the recovery distribution in a period in which they were confined to the southernmost areas. To enable a detailed analysis, territories to the north and south of the defined wintering grounds' boundary were divided into smaller areas. If a number of winter recoveries was low, then the data from larger regions were analysed (e.g. Central-Western Europe), whereas if recovery density was high, then distinguished areas were smaller. Division lines followed the state's borders.

Percent share of birds that returned to a defined sub-area during next and following winters was a measure of stabilization of this region as a wintering ground. All the defined areas were compared based on probability distributions of the following ratio: a number of Blackcaps noted in a given area during the winter following their winter of ringing ("winter zero") to a number of all Blackcaps recovered during winter in that area. Bayesian theory was applied in the calculations. According to this theory, a probability distribution of the "success" defined as a recovery of a bird in a given area during a winter following "winter zero" is a "beta" distribution (Spiegelhalter et al. 1999). Only recoveries of birds both ringed and recovered during winter were analysed.

Data from Spain were analysed in a different way. In this region the number of birds recovered during the same winter in which they had been ringed was unnaturally low compared to the number of recoveries from the following seasons. This is inconsistent with a general model of animal survival. A supplementary analysis (not included in this publication) showed that this was the characteristic of all data from Spain. Most probably the material was biased by some unknown errors. This was the reason why in the analysis of data from Spain an extrapolated value, based on the number of winter recoveries in two consecutive wintering seasons, was used in a given area, instead of a real (very low) number of recoveries of individuals ringed and recovered within the same winter. An average percentage by which the number of recoveries decreased from one season to the following one (in the first and second winter after ringing) was calculated. Then the number of recoveries in the first winter after ringing was increased by that calculated percentage. The result showed an approximate number of Blackcaps recovered during "winter zero" (Fig. 1). This is quite a rough estimation, so it is possible that the actual number of recoveries in "winter zero" was higher.

In the second step of the analysis, dates of Blackcaps' winter recoveries in selected areas were compared; here Kruskal-Wallis test and post-hoc Dunn test were applied.

In the third, final stage of the analysis, changes in the number of recoveries in areas to the north and south of the delimited wintering area boundary were followed over the last decades of the $\mathrm{XX}^{\text {th }}$ century. 


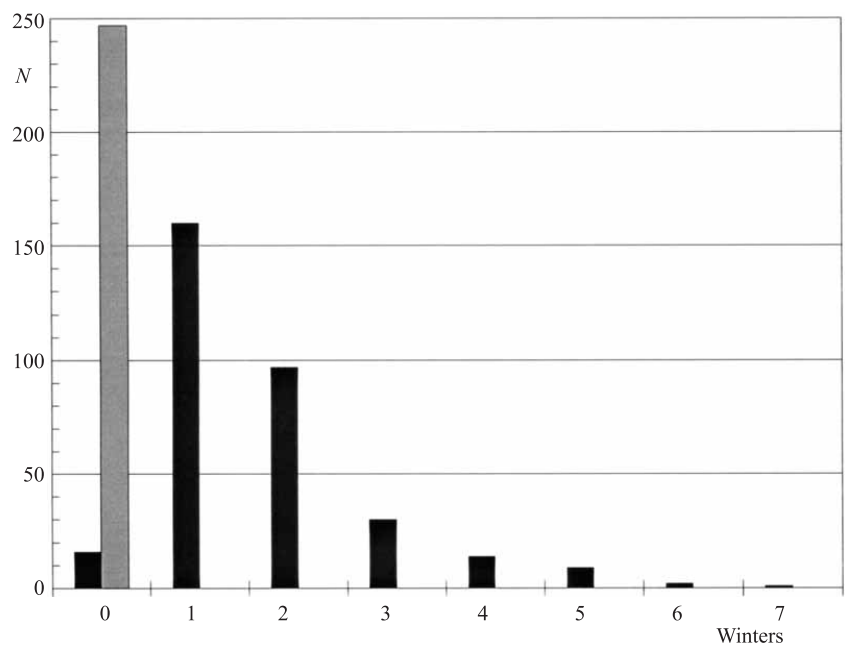

Fig. 1. Numbers of Blackcaps ringed in Spain in winter and recovered during the following winters. Grey bar a corrected number for the same winter (explanation in the text).

\section{RESULTS}

\section{Preliminary boundary of the wintering area}

An analysis of spatial distribution of Blackcaps' winter recoveries in subsequent ten-day periods showed that the recoveries of the species were limited to the southernmost parts of Europe in about mid-February (11-20 Feb.). Consequently, a preliminary northern boundary of the Blackcap wintering area in Europe was proposed according to the recovery distribution from the period mentioned above (Fig. 2). The boundary course in the eastern part of the wintering range is only approximate (marked with a dashed line on the map), due to a low number of winter recoveries in the region extending from the Balkans to the Middle East. In order to conduct detailed analyses the initially delimited wintering range of the Blackcap was divided into smaller areas (Fig. 3).

\section{Return rate - wintering area stability}

The return rate of Blackcaps during the following winters was analysed within the areas distinguished in continental Europe as well as in Great Britain. Northern Africa was excluded from this analysis as there were no data on birds ringed during winter there.

There were no recoveries from the following winters in Scandinavia. Predominance of recoveries from the same winter in which birds had been ringed ("winter zero") could be observed in Central-Western Europe. However, there was a slight fraction of Blackcaps that were recovered there during the following winters, although it was smaller than in the southern parts of Europe and in Great Britain (Table 1). In the Po 


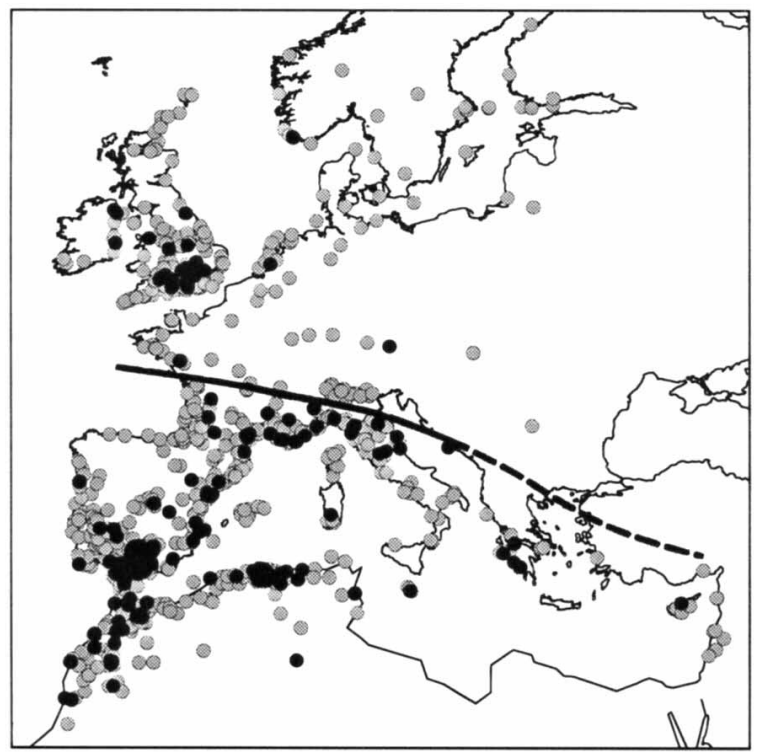

Fig. 2. Preliminary boundary of the Blackcap wintering area. Black dots - recoveries from the period of 11-20 Feb., grey dots - other winter recoveries.

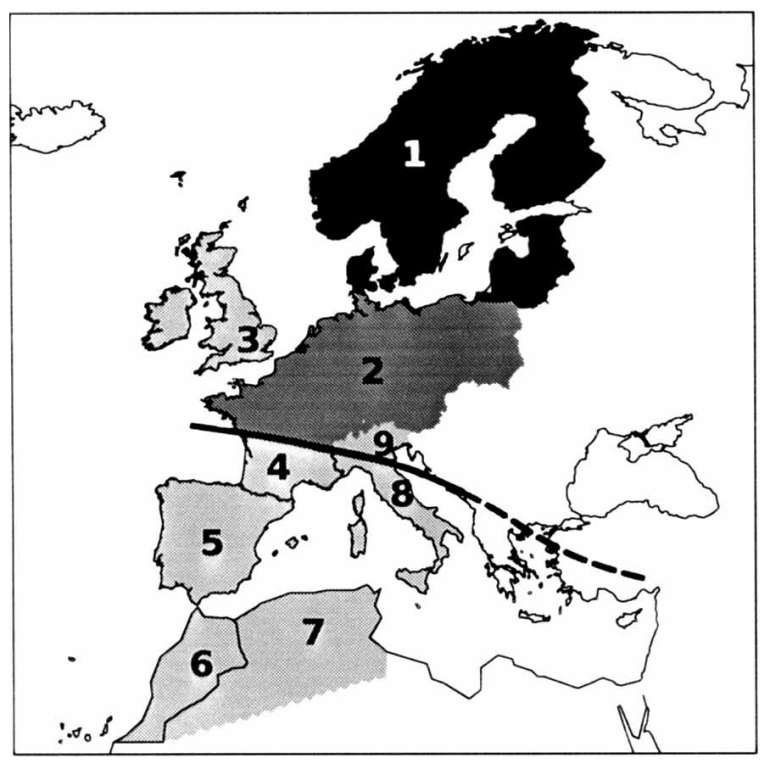

Fig. 3. Areas discussed in this study: 1 - Scandinavia, 2 - Central-Western Europe, 3 - Great Britain, 4 - Southern France, 5 - Spain, 6 - Morocco, 7 - Algeria and Tunisia, 8 - Italy, 9 Po Lowland. 
Lowland (Northern Italy) the recoveries from winters following the winter of ringing accounted for a half of all the winter recoveries. Moreover, the comparison of probability distributions for the analysed ratio between the Po Lowland and the remaining part of Italy showed a significant similarity of these two areas. For this reason in the return rate analysis both of them were considered as one territory. Taking into account the high return rate of Blackcaps during the following winters in the Po Lowland, the preliminary wintering area boundary was corrected and moved to the north (Fig. 4).

Table 1

Ratios of Blackcaps ringed in winter and recovered during the winter of ringing ("winter 0 ") and in the following winters in the distinguished areas

\begin{tabular}{|l|c|c|c|}
\hline \multirow{2}{*}{ Scandinavia } & "Winter 0" & Following winters & \multirow{2}{*}{$N$} \\
\cline { 2 - 3 } & \multicolumn{2}{|c|}{$\%$} & 18 \\
\hline Central-Western Europe & 100 & 0 & 21 \\
\hline Great Britain & 76 & 24 & 89 \\
\hline Southern France & 60 & 40 & 38 \\
\hline Southern Italy & 68 & 32 & 111 \\
\hline Northern Italy (Po Lowland) & 58 & 42 & 329 \\
\hline \multirow{2}{*}{ Spain } & 50 & 50 & $568 *$ \\
\cline { 2 - 4 } & 5 & 95 & $57^{*}$ \\
\hline
\end{tabular}

* according to extrapolated data, see Fig. 1 .

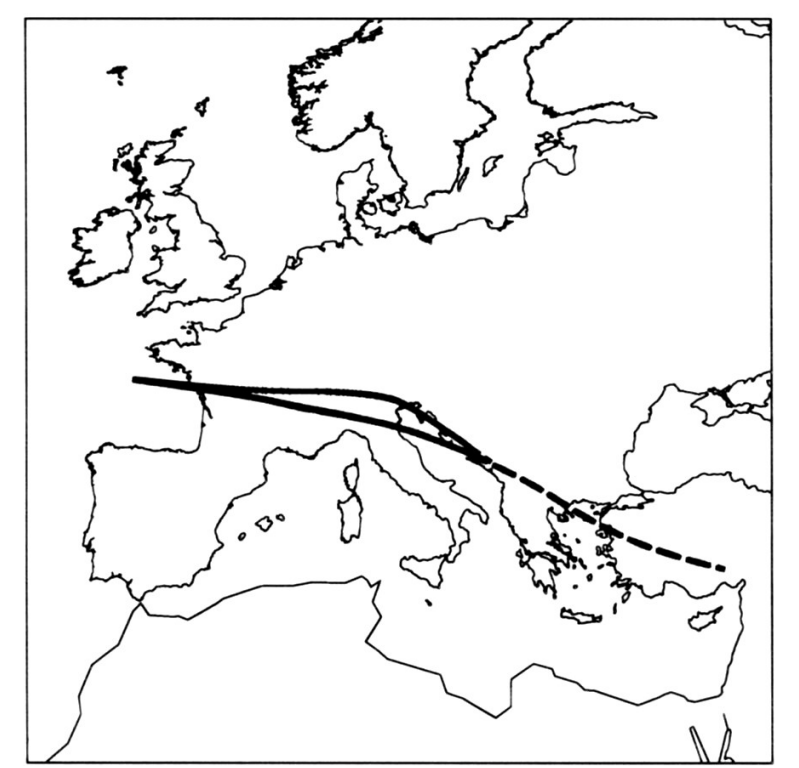

Fig. 4. Corrected boundary (shifted to the north) of the Blackcap wintering area. 
The comparison of probability distributions for the analysed proportion (Table 2) indicated that Scandinavia differed from all the remaining areas due to the fact that no Blackcaps were recovered there during the wintering seasons following the winter of their ringing. Spain was significantly different from all the compared areas, too, due to a very high birds' return rate observed on this wintering ground. In other cases the results were not so clear. According to the return rate analysis Great Britain was more similar to Italy (including the Po Lowland) and Southern France than to Central-Western Europe. There was some similarity in probability distributions for the analysed proportion between Central-Western Europe and Southern France, although it was lower than between Great Britain and Southern France.

Table 2

Probability distribution for the analysed return rate of Blackcaps in different areas. In bold - significant differences,

dark grey filling - significant similarities, grey filling - distinct similarity

\begin{tabular}{|l|c|c|c|c|c|}
\hline & $\begin{array}{c}\text { Central-Western } \\
\text { Europe }\end{array}$ & $\begin{array}{c}\text { Great } \\
\text { Britain }\end{array}$ & $\begin{array}{c}\text { Southern } \\
\text { France }\end{array}$ & Italy & Spain \\
\hline Scandinavia & $\mathbf{0 . 7 5 0 8 0}$ & $\mathbf{0 . 9 9 6 0 0}$ & $\mathbf{0 . 9 5 1 0 0}$ & $\mathbf{0 . 9 9 9 0 0 0}$ & $\mathbf{1 . 0 0 0}$ \\
\hline Central-Western Europe & & 0.3928 & 0.2605 & 0.5264 & $\mathbf{0 . 9 6 8 8 0}$ \\
\hline Great Britain & & & 0.2406 & 0.1665 & $\mathbf{0 . 9 6 8 6 0}$ \\
\hline Southern France & & & & 0.3333 & $\mathbf{0 . 9 6 7 9 0}$ \\
\hline Italy & & & & & $\mathbf{0 . 9 1 6 8 0}$ \\
\hline
\end{tabular}

\section{Recovery dates in selected areas}

A comparative analysis showed highly significant difference in recovery dates within all the analysed areas (Kruskal-Wallis test: $H=140.1, p<0.001$ ). Moreover, according to the analysis based on the post-hoc Dunn test, the territory of Scandinavia, where Blackcaps were noted at the beginning of winter, differed from all the other regions except for the Po Lowland and Central-Western Europe. Similarly Algeria and Tunisia were also significantly different from the other areas as Blackcaps were registered there exceptionally late (Fig. 5).

It can be expected that Blackcaps should be present on a regular wintering ground throughout the whole winter if conditions are favourable. Recovery dates in the Po Lowland as well as in Algeria and Tunisia were highly different from such an expectation. In the case of the Po Lowland there is no clear explanation for the early dates of recoveries, as the winter return rate analysis proved high Blackcaps' survival rate in this region. Thus, the lack of recoveries from the second part of winter most probably does not result from the lack of birds. Other exceptional areas were both Algeria and Tunisia, where Blackcaps were noted at the end of winter, or even on the turn of winter. Recovery dates indicated that birds could concentrate there at an early stage of spring migration. This could suggest that this area plays an important role in the Blackcap migration phenology. Because of all the reasons given above both the Po Lowland and Algeria were excluded from further stages of comparative analysis. 


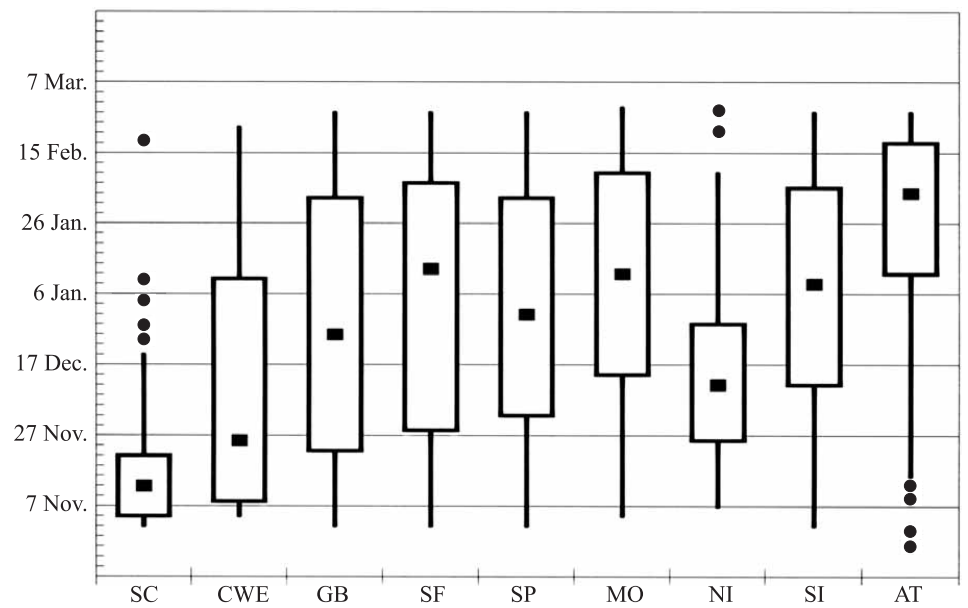

Fig. 5. Recovery dates in distinguished areas. SC - Scandinavia, CWE - Central-Western Europe, GB - Great Britain, SF - Southern France, SP - Spain, MO - Morocco, NI - Northern Italy (Po Lowland), SI - Southern Italy, AT - Algeria and Tunisia. Black rectangles average dates, white rectangles - $\pm S D$, lines - ranges, and dots - single recoveries.

When the post-hoc Dunn test was applied, it appeared that recovery dates in Scandinavia were highly significantly different from all the studied areas except CentralWestern Europe. However, that part of Europe differed significantly from Italy and Morocco. No differences were found between Great Britain and Central-Western Europe as well as between Great Britain and areas in the southern part of Europe (Table 3).

Table 3

Differences in the Blackcap recovery dates (according to the Dunn post hoc test) between the distinguished areas, except for the Po Lowland, Algeria and Tunisia

\begin{tabular}{|l|c|c|c|c|c|c|}
\hline & $\begin{array}{c}\text { Central-Wes- } \\
\text { tern Europe }\end{array}$ & $\begin{array}{c}\text { Great } \\
\text { Britain }\end{array}$ & Spain & S France & Italy & Morocco \\
\hline Scandinavia & $n s$ & $\boldsymbol{p}<\mathbf{0 . 0 0 1}$ & $\boldsymbol{p}<\mathbf{0 . 0 0 1}$ & $\boldsymbol{p}<\mathbf{0 . 0 0 1}$ & $\boldsymbol{p}<\mathbf{0 . 0 0 1}$ & $\boldsymbol{p}<\mathbf{0 . 0 0 1}$ \\
\hline Central-Western Europe & & $n s$ & $n s$ & $n s$ & $p<0.05$ & $p<0.05$ \\
\hline Great Britain & & & $n s$ & $n s$ & $n s$ & $n s$ \\
\hline Spain & & & & $n s$ & $n s$ & $n s$ \\
\hline S France & & & & & $n s$ & $n s$ \\
\hline Italy & & & & & & $n s$ \\
\hline
\end{tabular}

Changes in the number of Blackcaps wintering in Europe over the last decades of the $\mathrm{XX}^{\text {th }}$ century

To analyse this problem in detail, the whole area where the Blackcaps' winter recoveries were reported from was divided into three main regions: North (areas to the north of the wintering area northern boundary, i.e. Central-Western Europe and 
Scandinavia), South (areas to the south of the wintering area northern boundary) and Great Britain (Fig. 6).

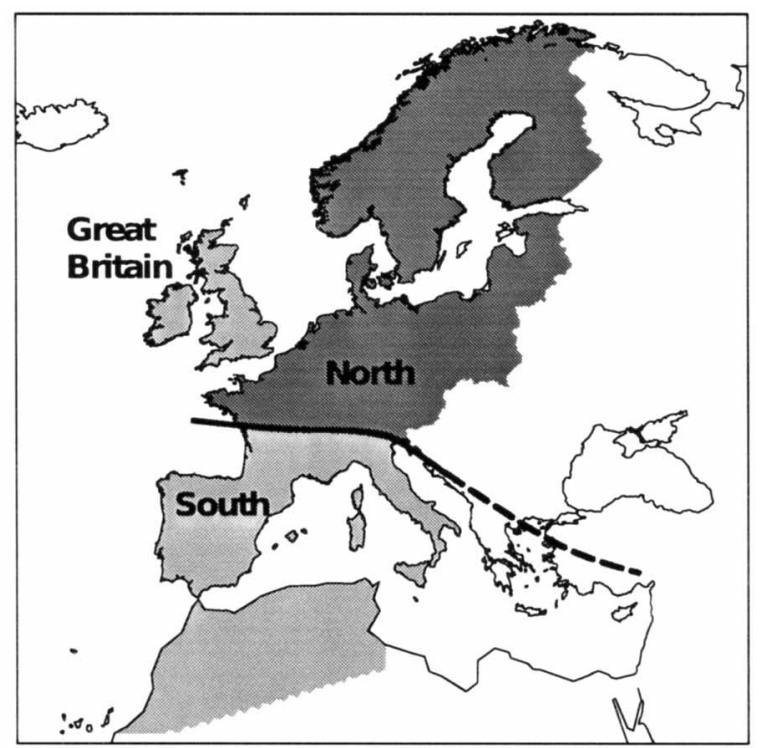

Fig. 6. Simplified division of the area covering the Blackcap winter recoveries.

Despite a large difference in recovery numbers for the North compared to the South, the curves reflecting changes in number of winter recoveries over the last decades of the $\mathrm{XX}^{\text {th }}$ century were very similar for these two regions (Fig. 7). However, the curve representing Great Britain was different. On this territory, in the 1970s and 1980s, a high increase in number of the Blackcaps' winter recoveries was observed, and this could reflect establishing a new wintering ground there. An increase in recovery number in Central-Western Europe and Scandinavia (North) most probably is not a result of increase in number of wintering birds, as similar trend was also observed in the southern part of Europe and the northern Africa (South), where Blackcaps have been wintering for hundreds of years.

\section{DISCUSSION}

Frequent reports on observations of wintering Blackcaps within the last decades were most probably a basis to delimit the northern boundary of the species wintering area farther to the north than in previous publications. According to Cramp (1992) as well as to Snow and Perrins (1998) the Blackcap wintering grounds cover substantial areas of Western Europe, including Denmark. Delimitation of the northern limit of the species wintering range so far to the North is probably an effect of more frequent reports on wintering Blackcaps in last decades rather than a real trend. However, 


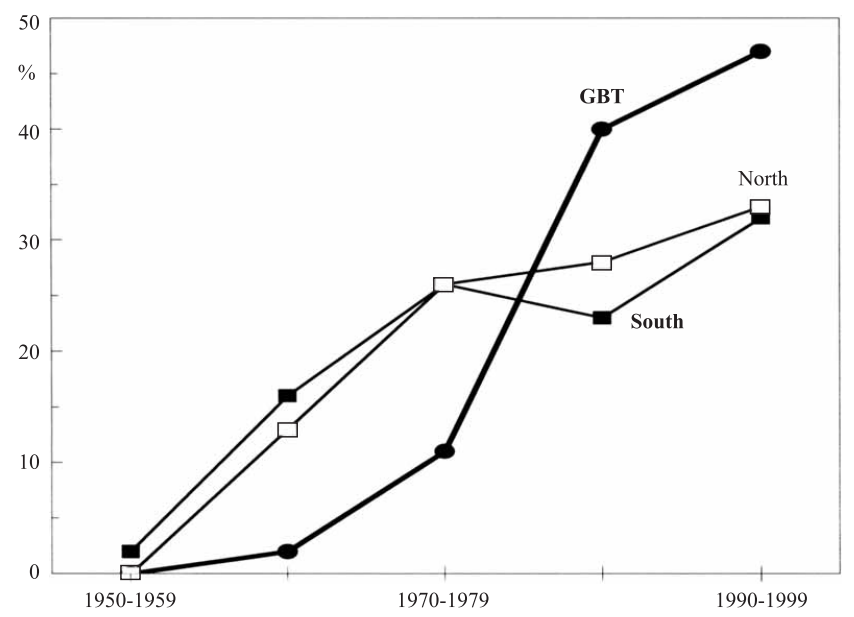

Fig. 7. Changes in number of winter recoveries in regions located in Great Britain and to the North and South of the Blackcap wintering area boundary over the last decades of the $\mathrm{XX}^{\text {th }}$ century.

according to Sovinc (1994) the Blackcap winters regularly in Slovenia only in the south-western part of the country, while in the rest of the territory it is recorded exceptionally. When considering location of Slovenia - quite far to the south, it can be assumed that climatic conditions of this region are much more favourable for the Blackcap wintering, compared e.g. to Denmark. It is probable that even numerous observations of these birds in central and northern Europe do not exactly mean that Blackcaps winter there regularly.

In this publication I assumed that a certain area became a stabilized wintering ground if it was not only the presence of wintering Blackcaps in that area that supported this assumption, but also the observations of these birds throughout the whole wintering season as well as their return to the same area in the following years. The Blackcap winter site fidelity was confirmed by, among others, Cuadrado et al. (1995). The preliminary delimitation of the wintering area northern boundary based on the records from the second part of February approximately defines an area where birds spent the whole winter, as opposed to the areas farther to the north from where birds disappear. We can only presume that they either left them because of unfavourable conditions or did not survive till the end of winter there. However, the species wintering area boundary based on these data had to be corrected, as a high return rate of birds to the area of the Po Lowland (northern Italy) during the following winters was observed. According to the LIPU-RSPB report (Lambertini and Tallone 1990) a traditional hunting season for small passerines (including Blackcaps) in Bresccia province in the northern Italy lasted from the end of September to the turn of December. And it exactly covered the period of reporting winter recoveries from this region. Thus, the lack of winter recoveries from the Po Lowland in the period 11-20 February, for which the preliminary wintering area boundary was defined, most probably results from the hunting season dates there. 
Another example of ringing recovery data limitation could be given from Spain. Despite a quite high number of recoveries from this region, there was almost a lack of data from the season in which birds were ringed ("winter zero"). An additional analysis of ringing recovery data of birds ringed in Spain showed that this phenomenon could be observed throughout the year. We may only suppose that data on birds controlled shortly after their ringing were not reported as recoveries to the Spanish Ringing Office. Data extrapolation for the "winter zero", based on the changes in recovery number in the next two seasons, gives an approximation of the actual number of recoveries in this period. However, one cannot be sure, whether observed, very high winter return rate in Spain does not result, at least to some extent, from too cautious assessment of the number of birds recovered in "winter zero".

The comparison of the Blackcap return rate in the distinguished wintering areas was based on the probability distribution analysis (Spiegelhalter et al. 1999). The ratio of the recovery number from other than "winter zero" seasons to the total recovery number of Blackcaps (ringed and recovered during winter) in a given area was analysed. In this respect Scandinavia, where there was lack of recoveries in the seasons later than "winter zero", as well as Spain, where the number of recoveries in "winter zero" could have been underestimated, differed significantly from the rest of compared areas. The method applied in this study allows not only to find significant differences but also to define similarity level. The results indicated that the Blackcap return rate in subsequent winters in Great Britain was quite similar to that in Southern France and Italy. This proves that despite quite a short history, this area became well-stabilized, regular wintering ground. Central-Western Europe according to the Blackcap return rate resembled only Southern France, but not so strongly as Great Britain did. The lack of such similarity between Central-Western Europe and Great Britain is also worth to be mentioned. Nevertheless, the low return rate of Blackcaps in Central-Western Europe during the following winters could indicate that an extension of the Blackcap wintering range to that area might be also possible.

The second criterion to assess whether a given area is a typical wintering ground of the species was the dates when birds were present there. It was assumed that if favourable conditions for the wintering of Blackcaps prevailed in a given region, then the individuals of the studied species would be observed there throughout the whole winter. The comparison of Blackcap winter recovery dates in distinguished areas showed that birds were observed in Scandinavia only at the beginning of winter and these dates differed significantly from the other regions except Central-Western Europe and the Po Lowland. The observed lack of difference in the Blackcap recovery dates between Scandinavia and the Po Lowland, most probably resulted from biased, as already mentioned, recovery dates of birds reported from the latter region. The Blackcap recovery dates from Central-Western Europe were mostly limited to the first half of winter, and that was so early in the season, that they differed significantly from the recovery dates not only from Algieria and Tunisia but also from Morocco and Italy. Therefore, it could be assumed that winter conditions were not favourable for survival of birds till the end of winter in this region. Obviously this did not exclude possibility that some individuals survived on the territory of Central-Western Europe every winter, furthermore, the Blackcap return rate in this region supported such 
a hypothesis as well. Nevertheless, it has to be assumed that most attempts of birds to spend winter there was unsuccessful.

Late recovery dates of Blackcaps in Algeria and Tunisia were a very interesting phenomenon. The birds were recorded there almost exclusively at the end of winter or even on the turn of winter, which is actually the beginning of return, spring migration to the north. Information on this could be found in several studies - e.g. from Malta (Sultana and Gauci 1977, 1983, 1988, 1990-1991; Zammit 1983; Coleiro 1988, 1989, 1990-1991; Coleiro and Attard-Montalto 1992-1994; Sultana et al. 1994; Mercieca et al. 1999), Italian islands (Spina et al. 1993) and northern Italy (Vigoritta and Reguzzoni 1997). The movements described in the above mentioned publications are most probably preceded by concentration of Blackcaps on the African coast - in Algeria and Tunisia. Nevertheless, an open question is from where Blackcaps that are recorded in Algeria at the end of winter migrate. This problem needs further analyses.

The analyses given in this study of both the Blackcap return rate in the selected areas and the recovery dates in these areas prove the establishing of a new wintering ground in Great Britain (Berthold and Terril 1989, Berthold et al. 1992, Busse 1992, Berthold 1995), and also indicate that Blackcaps can survive winter in CentralWestern Europe. These analyses show that there is a potential for change of the Blackcap wintering range. Taking into account information on global warming and numerous observations of Blackcaps in the parks and at bird tables during winter (Johansen 2002), a question whether such a change has already taken place becomes crucial. The recovery data analysis showed that in Central-Western Europe the number of winter recoveries was increasing regularly, although the rate of this increase was very similar to the changes in winter recovery number in southern wintering areas. Quite a different pattern was found in Great Britain - a wintering ground that formed, developed and stabilized during the last decades of the $\mathrm{XX}^{\text {th }}$ century. The observed increase in recovery number of wintering Blackcaps was much higher there. Thus, according to the results of this study, it cannot be assumed that the increase in number of the Blackcap winter recoveries for Central Western-Europe is a proof of the species wintering range expansion. Most probably this increase is rather an effect of so called „human factor”, which includes both a higher number of birds ringed in Europe during the last decades and growing public awareness of reporting on found rings. And this factor affects all European regions more or less to the same extent. A factor that most probably could advance the species wintering range expansion is the increased bird feeding activity. According to Pannach (2001) the Blackcap can survive even a considerable temperature drop. In Germany, when food was available, birds were able to survive even a short-term frost up to $-14^{\circ} \mathrm{C}$. Nevertheless, we still do not know whether the mechanism of wintering range expansion would result from migration routes' shortening, loss of migratory drive in breeding populations, or, as it was in the case of Great Britain, intentional, directional movements to new wintering areas (Berthold and Terrill 1988, Busse 1992). According to Fransson and Stolt (1993) Blackcaps that made attempts to winter in Sweden, originated from Central Europe, hence such a strategy of expanding wintering range to new territories cannot be excluded. 


\section{REFERENCES}

Bauer H.G., Boschert M., Hölzinger J. 1995. Die Vögel Baden-Würtembergs. Band 5. Atlas der Winterverbreitung. Artenschutzprogramms, Baden-Würtemberg.

Berndt R.K. 1996. Schlezwig-Holsteins Wintervogel im Wandel - eine Bilanz der Bestandsveranderungen 1970-1995. Corax 16: 356-372.

Berthold P. 1995. Microevolution of migratory behaviour illustrated by the Blackcap Sylvia atricapilla: 1993 Witherby Lecture. Bird Study 42: 89-100.

Berthold P., Helbig A.J., Mohr G., Querner U. 1992. Rapid microevolution of migratory behaviour in a wild bird species. Nature 360: 668-669.

Berthold P., Terril S.B. 1988. Migratory behaviour and population growth of Blackcaps wintering in Britain and Ireland: some hypotheses. Ring. \& Migr. 9: 153-159.

Busse P. 1992. Migratory behaviour of Blackcaps (Sylvia atricapilla) wintering in Britain and Ireland. Contradictory hypotheses. Ring 14: 51-75.

Coleiro C. 1988. Systematic List for 1985 \&1986. Il-Merill 25: 19-41.

Coleiro C. 1989. Systematic List for 1987-88. Il-Merill 26: 1-27.

Coleiro C. 1990-1991. Systematic List for 1989. I1-Merill 27: 30-47.

Coleiro C., Attard-Montalto J. 1992-1994. Systematic List for 1990-92. Il-Merill 28: 38-65.

Cramp S. 1992. Handbook of the Birds of Europe, the Middle East and North Africa. The Birds of the Western Palearctic. vol. 4. Oxford Univ. Press, Oxford.

Cuadrado M., Rodriguez M., Arjona S. 1989. Fat and weight variations of Blackcaps wintering in southern Spain. Ring. \& Migr. 10: 89-97.

Fransson T., Stolt B.O. 1993. Is there an autumn migration in continental Blackcaps (Sylvia atricapilla) into northern Europe? Vogelwarte 37: 89-95.

Fransson T., Stolt B.O. 1994. The wintering of Blackcaps Sylvia atricapilla in Sweden. Ornis Svec. 4: $105-112$.

Górski W., Misiewicz. A, Owczarek A., Zielonka M. 1980. Rzadkie nielęgowe gatunki ptaków obserwowane na Wybrzeżu Środkowym w latach 1977-1979. Not. Orn. 21: 82-85.

Harrison C. 1982. An Atlas of the Birds of the Western Palearctic. Collins, London.

Johansen B.T. 2002. Vinterforekomst oa Munk Sylvia atricapilla i Danmark. Dansk. Orn. Foren. Tidsskr. 96: 68-74.

Klein H., Berthold P., Gwinner E. 1973. Der Zug europaischer Garten- und Monchgrassmucken (Sylvia borin und Sylvia atricapilla). Vogelwarte 27: 73-134.

Lafferère M. 1987. La Fauvette à Tête Noire Sylvia atricapilla. Un hôte d'hiver dont l'observation est occasionnnelle. Alauda 55: 227-229.

Lambertini M., Tallone G. 1990. Bird killing in Italy. LIPU-RSPB, Parma.

Mercieca C., Mallia M., Sultana J. 1999. Systematic List for 1993-95. I1-Merill 29: 30-58.

Pannach G. 2001. Wintervorkommen von Mönchgrasmücken Sylvia atricapilla in Nidersachsen. Ornit. Mitt. 53: 387-390.

Snow D. W., Perrins C. M. 1998. The Birds of the Western Palearctic. Oxford Univ. Press.

Sovinc A. 1994. The Atlas of Wintering Birds in Slovenia.. Tehniška založba Slovenije, Ljubljana.

Spiegelhalter D.J, Myles J.P., Jones D.R., Abrams K.R. 1999. Methods in health service research: An introduction to bayesian methods in health technology assessment. BMJ 319: 508-519.

Spina F., Massi A., Montemaggiori A., Baccetti N. 1993. Spring migration across Central Mediterranean: general results from the 'Progretto Piccole Isole'. Vogelwarte 37 (Suppl.): 1-94.

Sultana J., Gauci C. 1977. Report on Bird-Ringing for 1975 and 1976. Il-Merill 18: 1-18.

Sultana J., Gauci C. 1983. Ringing Report for 1979-81. Il-Meril 22: 43-56.

Sultana J., Gauci C. 1988. Ringing Report for 1986-87. Il-Meril 25: 41-52.

Sultana J., Gauci C. 1990-1991. Ringing Report for 1989. Il-Meril 27: 47-56. 
Sultana J., Gauci C., Gauci M. 1994. Ringing Report for 1990-1993. Il-Merill 22: 65-77.

Tomiałojć L., Stawarczyk T. 2003. Awifauna Polski. Rozmieszczenie, liczebność i zmiany. PTPP „pro Natura”, Wrocław.

Vigorita V., Reguzzoni P.A. 1997. Attivita'di inanelamento. Osservatori ornitologici XXI: 14-18.

Yeatman-Berthelot D. 1991. Atlas de Oiseaux de France en hiver. Société Ornithologique de France, Paris.

Zammit R.C. 1983. Systematic List for 1979 \& 1980. Il-Merill 22: 22-43. 